\title{
Therapeutic effect of Schistosoma japonicum cystatin on bacterial sepsis in mice
}

Huihui $\mathrm{Li}^{1,2 \dagger}$, Shushu Wang ${ }^{3 \dagger}$, Bin Zhan ${ }^{4 \dagger}$, Wenxin He ${ }^{1,2}$, Liang Chu ${ }^{5}$, Dapeng Qiu ${ }^{5}$, Nan Li ${ }^{1}$, Yongkun Wan ${ }^{1}$, Hui Zhang ${ }^{1}$, Xingzhi Chen ${ }^{1}$, Qiang Fang ${ }^{1}$, Jilong Shen ${ }^{6}$ and Xiaodi Yang ${ }^{1,2^{*}}$

\begin{abstract}
Background: Sepsis is a life-threatening complication of an infection and remains one of the leading causes of mortality in surgical patients. Bacteremia induces excessive inflammatory responses that result in multiple organ damage. Chronic helminth infection and helminth-derived materials have been found to immunomodulate host immune system to reduce inflammation against some allergic or inflammatory diseases. Schistosoma japonicum cystatin (Sj-Cys) is a cysteine protease inhibitor that induces regulatory T-cells and a potential immunomodulatory. The effect of Sj-Cys on reducing sepsis inflammation and mortality was investigated.

Methods: Sepsis was induced in BALB/C mice using cecal ligation and puncture (CLP), followed by intraperitoneal injection of different doses (10, 25 or $50 \mu \mathrm{g}$ ) of recombinant Sj-Cys (rSj-Cys). The therapeutic effect of rSj-Cys on sepsis was evaluated by observing the survival rates of mice for $96 \mathrm{~h}$ after CLP and the pathological injury of liver, kidney and lung by measuring the levels of alanine transaminase (ALT), aspartate transaminase (AST), blood urea nitrogen (BUN) and creatinine $(\mathrm{Cr})$ in sera and the tissue sections pathology, and the expression of MyD88 in liver, kidney and lung tissues. The immunological mechanism was investigated by examining pro-inflammatory cytokines (TNF- $\alpha, I L-6, I L-1 \beta$ ) and IL-10 and TGF- $\beta 1$ in mice sera and in culture of macrophages stimulated by lipopolysaccharides (LPS).

Results: rSj-Cys treatment provided significant therapeutic effects on CLP-induced sepsis in mice demonstrated with increased survival rates, alleviated overall disease severity and tissue injury of liver, kidney and lung. The rSj-Cys conferred therapeutic efficacy was associated with upregualted IL-10 and TGF- $\beta 1$ cytokines and reduced proinflammatory cytokines TNF- $a$, IL-6, IL-1 $\beta$. MyD88 expression in liver, kidney and lung tissues of rSj-Cys-treated mice was reduced. In vitro assay with macrophages also showed that rSj-Cys inhibited the release of pro-inflammatory cytokines and mediator nitric oxide (NO) after being stimulated by lipopolysaccharide (LPS).

Conclusions: The results suggest the anti-inflammatory potential of rSj-Cys as a promising therapeutic agent on sepsis. The immunological mechanism underlying its therapeutic effect may involve the downregulation of proinflammatory cytokines and upregulation of IL-10 and TGF- $\beta 1$ cytokines possibly via downregulation of the TLR adaptor-transducer MyD88 pathway. The findings suggest rSj-Cys is a potential therapeutic agent for sepsis and other inflammatory diseases.
\end{abstract}

Keywords: Cystatin, Schistosoma japonicum, Sepsis, Cecal ligation and puncture, Immunomodulation

\footnotetext{
*Correspondence: yxd_qf@163.com

${ }^{\dagger}$ Equal contributors

${ }^{1}$ Basic Medical College of Bengbu Medical College, Bengbu 233000, China

${ }^{2}$ Anhui Key Laboratory of Infection and Immunity of Bengbu Medical

College, Bengbu 233000, China

Full list of author information is available at the end of the article
} International License (http://creativecommons.org/licenses/by/4.0/), which permits unrestricted use, distribution, and reproduction in any medium, provided you give appropriate credit to the original author(s) and the source, provide a link to the Creative Commons license, and indicate if changes were made. The Creative Commons Public Domain Dedication waiver (http://creativecommons.org/publicdomain/zero/1.0/) applies to the data made available in this article, unless otherwise stated. 


\section{Background}

Sepsis is one of most serious complications of clinical critical patients with infections $[1,2]$. Although extensive research has made some progress in several fields of sepsis, the appropriate therapeutic intervention is limited and sepsis is still associated with high morbidity and mortality worldwide [3, 4]. In sepsis, bacterial lipopolysaccharide (LPS) endotoxin induces macrophages and other effective cells to release massive pro-inflammatory cytokines which play pivotal roles in the development of systemic inflammatory responses [5, 6]. The excessive inflammatory responses damage the structure and function of vital organs such as kidney, liver and lung [7-11], and even lead to multiple organ dysfunction syndromes (MODS) and death. Therefore, how to inhibit the release of pro-inflammatory cytokines and balance immune response has been suggested as an important strategy to treat sepsis and reduce its mortality.

Helminthic infections trigger Th2-skewed immune responses characterized by activated Th2 cells and related cytokines including high levels of IgE, IgG1 and eosinophils [12]. During infection in host, helminth worms secret a variety of molecules to modulate host immune responses as a strategy to escape host immune attack [13]. The immunomodulatory effect usually takes effect through stimulation of regulatory $\mathrm{T}$ cells (Tregs) characterized by increased level of IL-10, TGF- $\beta 1$ and FoxP3 $^{+} \mathrm{T}$ cells [14]. The effect of immunomodulation protects worms from being attacked by host immune defense; on the other hand it balances host immune system to reduce susceptibility to autoimmune or allergic diseases caused usually by hypersensitivity to endogenous self-antigens or exogenous allergens [15]. This concept has been adopted to use helminth infection or helminth-derived proteins to treat a variety of allergic or autoimmune diseases and significant relief of these diseases has been observed [16-18].

Helminths secrete various cysteine protease inhibitors called cystatins [19] which play important roles in escaping host immune attack by directly inhibiting host cysteine proteases or suppressing host immune response through regulating inflammatory cytokines [20-28] or inhibiting class II MHC-restricted antigen processing and antigen epitope presentation [22], therefore cystatins from various parasitic helminths are being explored as potential therapeutic agents for allergic diseases or immunological disorders including allergic asthma [26], inflammatory colitis [27, 29], and collagen-induced arthritis [30]. The cystatin from the blood-feeding trematode Schistosoma japonicum (Sj-Cys) has been identified not only to inhibit the proteolytic activity of cysteine protease papain [31], but also to inhibit the release of proinflammatory cytokines such as TNF- $\alpha$ and IL-6 from RAW264.7 induced by LPS in vitro [25]. Whether Sj-
Cys inhibits the release of pro-inflammatory cytokines during serious infection and whether $\mathrm{Sj}$-Cys can be used as a therapeutic agent for sepsis have not been investigated so far.

In the present study, we investigated the therapeutic effect of recombinant $\mathrm{Sj}$-Cys (rSj-Cys) on sepsis using a cecal ligation and puncture (CLP)-induced sepsis mice model. We identified that the administration of $\mathrm{rSj}$-Cys significantly reduced the mortality of CLP-induced sepsis and its therapeutic effect took effect through inhibiting the pro-inflammatory cytokines and boosting IL-10 and TGF- $\beta 1$ cytokines, providing a promising strategy for sepsis therapy in clinical practice.

\section{Methods}

\section{Production of recombinant Sj-Cys protein}

DNA coding for full-length Sj-Cys (GenBank: CAX7 3577.1) was amplified from total cDNA of S. japonicum adult worms using following primers (forward: 5'-CAG AAT TCA TGC CTT TAT GTT GTG GTG GT G-3'; reverse: 5'-GCC TCG AGT TAG AAA TAA TAG AAA TGT AAC AGC-3') and cloned into pET-28a (+) (Promega, Madison, Wisconsin, USA) using EcoRI and XhoI restriction sites. The sequencing-confirmed recombinant plasmid was transformed into E. coli $\mathrm{BL} 21$. The expression of $\mathrm{rSj}$-Cys was induced with $1 \mathrm{mM}$ isopropylthio$\beta$-galactoside (IPTG, Sigma-Aldrich, Steinheim, Germany) at $37{ }^{\circ} \mathrm{C}$ for $5 \mathrm{~h}$. The expressed $\mathrm{rSj}$-Cys with His-tag at $\mathrm{N}$-terminus was purified with a Ni-NTA His* Bind Purification Kit (Merck Millipore, Basilica, Massachusetts, USA). The contaminated endotoxin in purified $\mathrm{rSj}$-Cys was removed by using a ToxOut ${ }^{\mathrm{TM}}$ High Capacity Endotoxin Removal Kit (BioVision, Palo Alto, California, USA) and detected by ToxinSensor ${ }^{\text {TM }}$ Chromogenic Limulus Amebocyte Lysate (LAL) Endotoxin Assay Kit (GenScript Biotechnology, Nanjing, China) following the manufacturer's protocol. The concentration of $\mathrm{rSj}$-Cys was measured using Bicinchoninic Acid Protein Assay Kit (Beyotime Biotechnology, Shanghai, China).

\section{Preparation and stimulation of murine peritoneal exudate cells}

Donor BALB/c mice were euthanized and the murine peritoneal exudate cells (PECs) were collected by washing the peritoneal cavity with $5 \mathrm{ml}$ of ice-cold phosphate-buffered saline (PBS) supplemented with $2 \%$ heat-inactivated fetal bovine serum (FBS) (Zhejiang Tianhang Biological Technology, Zhejiang, China) as described in [32]. The recovered cells were washed three times with PBS and resuspended in RPMI 1640 medium supplemented with 10\% FBS, $100 \mathrm{U} / \mathrm{ml}$ penicillin and $100 \mu \mathrm{g} / \mathrm{ml}$ streptomycin (Sigma-Aldrich, Steinheim, Germany). The cells were coated on 24-well plate $\left(2 \times 10^{6}\right.$ cells/well in $\left.1 \mathrm{ml}\right)$ at $5 \%$ $\mathrm{CO}_{2}, 37^{\circ} \mathrm{C}$ for $4 \mathrm{~h}$. The non-adherent cells were removed 
by washing with RPMI 1640 and the adherent cells were stimulated with LPS $(2 \mu \mathrm{g} / \mathrm{ml})$ (Sigma-Aldrich, Steinheim, Germany, USA) in the presence of $\mathrm{rSj}$-Cys $(2 \mu \mathrm{g} / \mathrm{ml})$ for $24 \mathrm{~h}$. The concentrations of TNF- $\alpha$, IL-6, IL-1 $\beta$ in the culture supernatants were measured using LEGEND MAX ${ }^{\mathrm{sm}}$ ELISA kits (Dakewe Biotech, Beijing, China) and nitric oxide (NO) was measured by nitrate reductase method using NO assay kit (Nanjing Jiancheng Bio-engineering Institute, Nanjing, China) according to the manufacturer's instruction.

\section{Animals and cecal ligation and puncture-induced sepsis}

Male BALB/C mice (specific pathogen free) with 6-8 weeks old and weighing 18-22 g, were purchased from the Animal Center of Anhui Medical University and maintained in a controlled environment (12:12 h light/dark cycle with a temperature of $22 \pm 2{ }^{\circ} \mathrm{C}$ and a relative humidity of $55 \%$ ). Water and food were provided ad libitum.

A clinically relevant rodent model of sepsis was created by cecal ligation and puncture (CLP) based on the method described in [3]. Briefly, mice were fasted for $12 \mathrm{~h}$ with drinking water only and then anaesthetized by intraperitoneal injection of chloral hydrate $(40 \mathrm{~g} / \mathrm{l}) 0.2 \mathrm{ml} / 20 \mathrm{~g}$. The abdominal cavity was opened with a midline incision in layers. The cecum was isolated and ligated $1.0 \mathrm{~cm}$ from the tip. A through-and-through puncture was made with an 18-gauge needle and a small amount of feces was extruded to ensure the patency of the puncture site before returning the cecum back to the abdominal cavity. Each layer opened was closed with suture. The control mice underwent a sham surgery receiving a laparotomy without cecal ligation and puncture. The general condition and survival rate of mice were observed for the following 4 days.

\section{Treatment of CLP-induced sepsis with rSj-Cys}

Mice were divided into 5 groups, four groups of 16 mice each were CLP operated and treated intraperitoneally with $10 \mu \mathrm{g}, 25 \mu \mathrm{g}$ and $50 \mu \mathrm{g}$ of $\mathrm{rSj}$-Cys or PBS in a total volume of $200 \mu \mathrm{l} 30 \mathrm{~min}$ after surgery, respectively. Another group of 16 mice were performed sham surgery without ligation and puncture of the cecum and given with PBS only. Six mice in each group were sacrificed $12 \mathrm{~h}$ after surgery for measuring inflammatory cytokines and biomarkers of tissue injury in blood and pathology of liver, kidney and lung. The remaining 10 mice were observed for general physical conditions and survival rate for $96 \mathrm{~h}$. The survival rates were determined using Kaplan-Meier method.

\section{Serological evaluation of sepsis-caused liver and kidney injury and cytokine changes}

Blood samples were collected $12 \mathrm{~h}$ after surgery, and sera were saved for measuring the levels of alanine transaminase
(ALT), aspartate transaminase (AST), blood urea nitrogen (BUN) and creatinine ( $\mathrm{Cr}$ ) by automatic chemistry analyzer (Beckman Coulter, Brea, California, USA) to evaluate sepsis-caused liver and kidney injury. The serum levels of pro-inflammatory cytokines (TNF- $\alpha$, IL- 6 and IL-1 $\beta$ ) and IL-10 and TGF- $\beta 1$ cytokines were measured using LEGEND MAX ${ }^{\mathrm{mm}}$ ELISA kits (Dakewe Biotech, Beijing, China) following the manufacturer's instructions.

\section{Macroscopic and histopathological changes in liver, kidney and lung}

The liver, kidney and lung tissues were collected from each mice $12 \mathrm{~h}$ after surgery, and fixed with $4 \%$ paraformaldehyde. The tissue sections were stained with hematoxylin and eosin and observed under a microscope (Olympus, Tokyo, Japan). The histological liver injury was scored based on hepatocellular necrosis, bleeding, and inflammatory cell infiltration in the liver [33] as shown in Table 1. The histological kidney injury was scored based on the injured renal tubules and shrunk glomerulus [34, 35] as shown in Table 2. The histological lung injury was scored based on the alveolar congestion, hemorrhage, neutrophil infiltration into the airspace or vessel wall, and thickness of alveolar wall/hyaline membrane formation [36] as shown in Table 3. Histopathological changes in the liver, kidney and lung tissues were blindly reviewed and scored as described above.

\section{Western blot detection of MyD88 in liver, kidney and lung tissues of mice}

The liver, kidney and lung tissues of mice were homogenized and separated by $12 \%$ polyacrylamide gel electrophoresis. Proteins were blotted onto a $0.45 \mu \mathrm{m}$ polyvinylidene fluoride (PVDF) membrane. Rabbit anti-MyD88 monoclonal antibody (Cell Signaling Technology, Danvers, Massachusetts, USA) $(1: 1,000)$ and rabbit anti- $\beta$-actin polyclonal antibody (Cell Signaling Technology, Danvers, Massachusetts, USA) (1:2,000) were used to probe MyD88 and $\beta$-actin in mice tissues. HRP-conjugated goat antirabbit IgG (Merck Millipore, Basilica, Massachusetts, USA) was used as secondary antibody at 1:10,000 dilution. The density of recognized MyD88 was compared to that of control $\beta$-actin and their ratio was used as a relative expression level of MyD88 in injured mice tissues.

Table 1 Liver injury score parameters

\begin{tabular}{|c|c|c|c|c|c|}
\hline Index & 0 & 1 & 2 & 3 & Maximum \\
\hline Necrosis & None & $\begin{array}{l}\text { Focal } \\
\text { piecemeal }\end{array}$ & $\begin{array}{l}\text { Continuous } \\
<50 \%\end{array}$ & $\begin{array}{l}\text { Continuous } \\
>50 \%\end{array}$ & 3 \\
\hline Bleeding & None & $<30 \%$ & $30-50 \%$ & $>50 \%$ & 3 \\
\hline Infiltration & None & 2- to 3-fold & 3- to 10-fold & $>10$-fold & 3 \\
\hline
\end{tabular}


Table 2 Kidney injury score parameters

\begin{tabular}{ll}
\hline Injured renal tubules and shrunk glomerulus & Index \\
\hline None & 0 \\
$<10 \%$ & 1 \\
$11-25 \%$ & 2 \\
$26-45 \%$ & 3 \\
$46-75 \%$ & 4 \\
$>76 \%$ & 5 \\
\hline
\end{tabular}

\section{Statistical analysis}

All data were presented as the mean \pm SEM (standard error of the mean), and the statistical analyses were performed using SPSS 16.0 software. Comparison of the same parameters in multiple datasets or more than two groups was done using one-way analysis of variance (ANOVA). The difference in survival rates among the groups was compared using Kaplan-Meier survival analysis. $P<0.05$ was considered as statistically significant.

\section{Results}

\section{Expression, purification and identification of $\mathrm{rSj}$-Cys}

The $\mathrm{rSj}$-Cys was successfully expressed in $E$. coli as soluble recombinant protein. SDS-PAGE showed that the purified $\mathrm{rSj}$-Cys appeared as size of about $11 \mathrm{kDa}$, which corresponds well to the molecular weight of deduced peptide gene product $(11.3 \mathrm{kDa})$ (Fig. 1). The contaminated endotoxin level in purified rSj-Cys was as less than $0.06 \mathrm{EU} / \mathrm{ml}$ after running through the endotoxin removal column.

\section{The inhibitory effects of $r S j$-Cys on murine peritoneal} exudate cells upon LPS stimulation

Upon stimulation of LPS at concentration of $2 \mu \mathrm{g} / \mathrm{ml}$, adherent murine peritoneal exudate cells (PECs), mostly macrophages, secreted high levels of proinflammatory cytokines including TNF- $\alpha$, IL-6 and IL$1 \beta$ (ANOVA: $F_{(3,23)}=41.00, P<0.0001 ; F_{(3,23)}=46.04, P$ $<0.0001 ; F_{(3,23)}=11.70, P<0.0001$, respectively) and released more inflammatory mediator nitrous oxide (NO)

Table 3 Lung injury score parameters

\begin{tabular}{lc}
\hline Changes of lung tissues structure & Index \\
\hline None & 1 \\
$\begin{array}{l}\text { Focal interstitial congestion and inflammatory cell } \\
\text { infiltration }<50 \%\end{array}$ & 2 \\
$\begin{array}{l}\text { Diffuse interstitial congestion and inflammatory cell } \\
\text { infiltration }>50 \%\end{array}$ & 3 \\
Focal consolidation and inflammatory cell infiltration $<50 \%$ & 4 \\
Diffuse consolidation and inflammatory cell infiltration $>50 \%$ & 5 \\
\hline
\end{tabular}

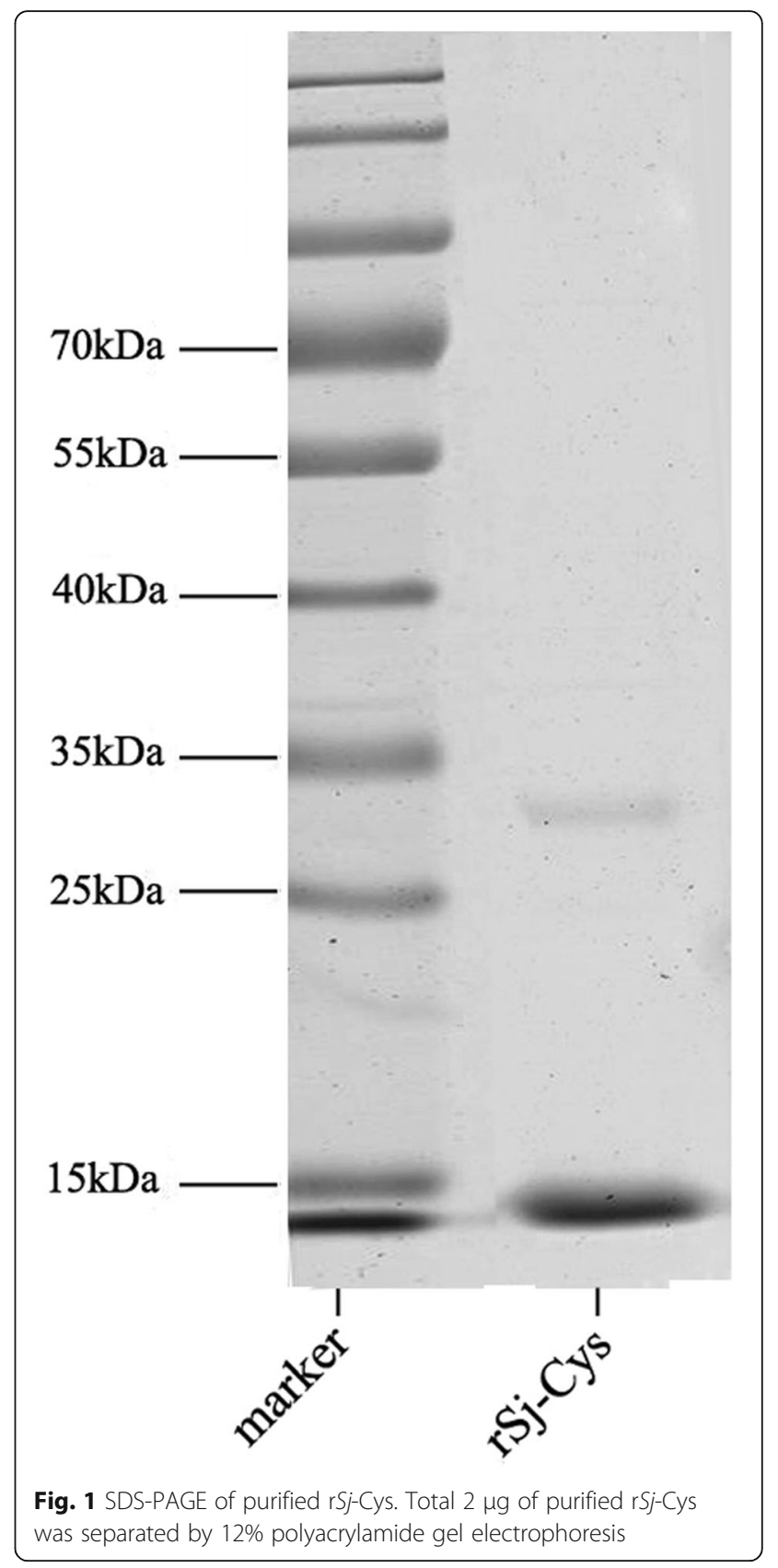

(ANOVA: $\left.F_{(3,23)}=39.02, P<0.0001\right)$ compared to cells incubated with RPMI 1640 alone. The addition of rSj-Cys $(2 \mu \mathrm{g} / \mathrm{ml})$ significantly inhibited PECs to secrete TNF- $\alpha$, IL-6, IL-1 $\beta$ and NO upon stimulation of LPS compared to cells in LPS stimulation without rSj-Cys (ANOVA: $F_{(3,23)}$ 41.00, $\quad P<0.0001 ; \quad F_{(3,23)}=46.04, \quad P<0.0001 ; \quad F_{(3,23)}=$ $11.70, P<0.0001 ; F_{(3,23)}=39.02, P<0.0001$, respectively) (Fig. 2), indicating that $\mathrm{rSj}$-Cys suppresses the macrophages pro-inflammatory release to LPS stimulation. $\mathrm{rSj}$ Cys itself stimulated low level of TNF- $\alpha$, IL-6, IL-1 $\beta$ and NO released by PECs. 

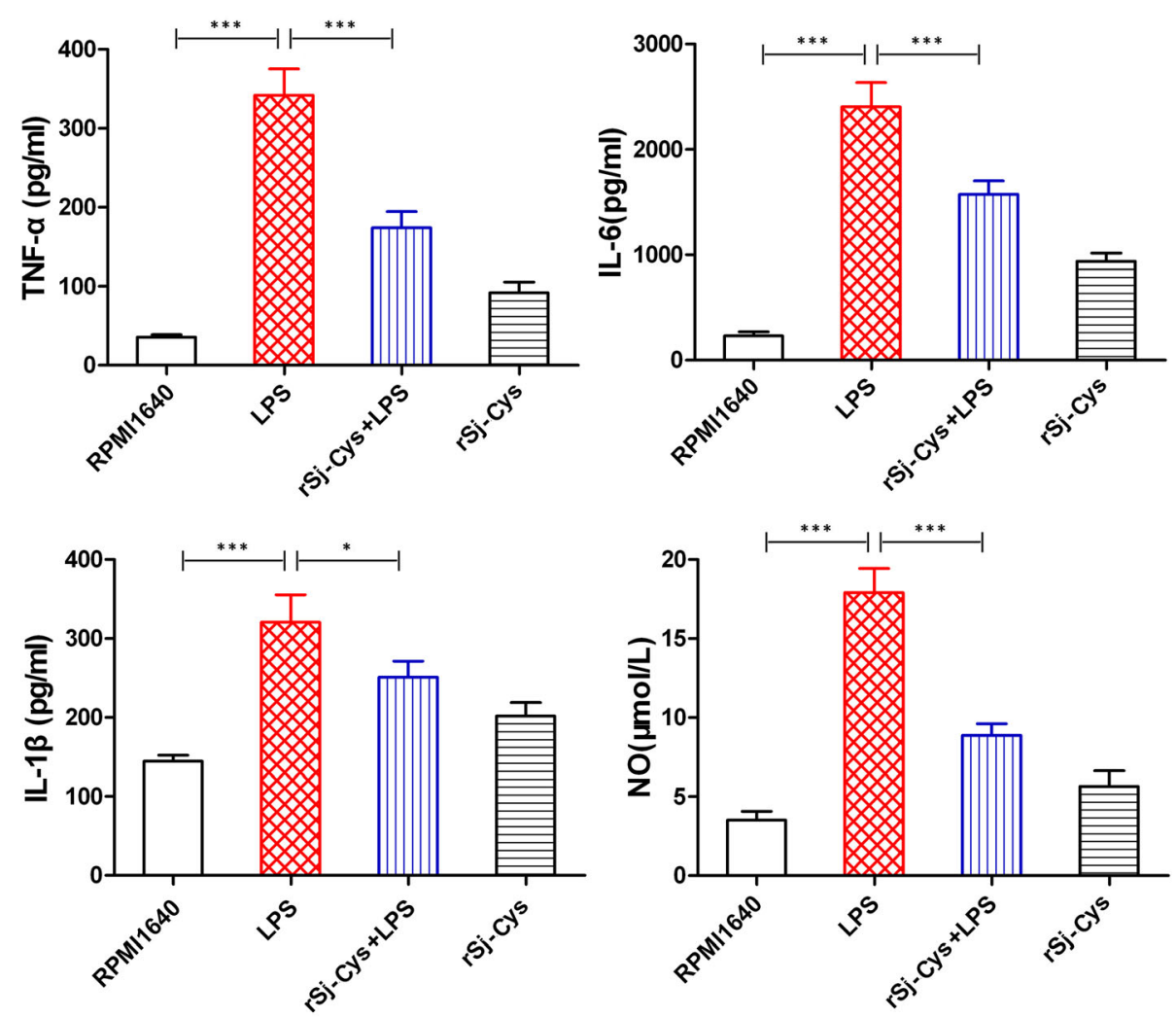

Fig. $2 \mathrm{rSj}$-Cys reduces the releasing of pro-inflammatory cytokines and nitrous oxide from murine peritoneal exudate cells stimulated with LPS. The adherent peritoneal exudate cells were cultured and stimulated with LPS in the presence or absence of rSj-Cys. The levels of TNF-a, IL-6, IL-1 $\beta$ and $\mathrm{NO}$ were measured in culture supernatants collected after $24 \mathrm{~h}$ incubation. The results are shown as the mean \pm SEM for each group. ${ }^{*} P<0.05,{ }^{* * *} P<0.001$

\section{rSj-Cys ameliorates CLP-induced sepsis}

rSj-Cys was used to treat CLP-induced sepsis in a mouse model to determine whether it is able to ameliorate sepsis. As shown in Fig. 3, CLP induced severe sepsis with all mice died $55 \mathrm{~h}$ after surgery without treatment (Kaplan-Meier analysis compared with sham group: $\chi^{2}=$ 21.84, $d f=1, P<0.0001)$. However, mice treated with rSj-Cys 30 min after the CLP surgery significantly reduced their mortality caused by sepsis. Compared to mice with sepsis without treatment, mice treated with $10 \mu \mathrm{g} \mathrm{rSj-Cys}$ had a survival rate of $80 \% 96 \mathrm{~h}$ after CLP surgery (Kaplan-Meier analysis: $X^{2}=16.63, d f=1, P<$ $0.0001)$ while mice treated with $25 \mu \mathrm{g}$ or $50 \mu \mathrm{g}$ of $\mathrm{rSj}$ Cys had a survival rate of $70 \%$ (Kaplan-Meier analysis: $\chi^{2}=13.23, d f=1, P=0.0003$ ) and 60\% (Kaplan-Meier analysis: $\chi^{2}=9.32, d f=1, P=0.0023$ ), respectively (Fig. 3). Mice with sham surgery all survived for $96 \mathrm{~h}$ period.

\section{rSj-Cys inhibits pro-inflammatory cytokines and induces} IL-10 and TGF- $\beta 1$ in mice with CLP-induced sepsis

Sepsis is characterized by surged pro-inflammatory cytokines in circulating blood [37]. We examined the serum levels of some pro-inflammatory cytokines in mice with sepsis treated with or without $\mathrm{rSj}$-Cys to investigate whether $\mathrm{rSj}$-Cys rescues mice with sepsis through inhibiting inflammatory cytokine storm. The results demonstrated that serum levels of the pro-inflammatory cytokines (TNF- $\alpha$, IL-6 and IL-1 $\beta$ ) were dramatically increased in mice with sepsis $12 \mathrm{~h}$ after CLP surgery compared to mice with sham surgery (ANOVA: $F_{(4,29)}=$ 40.17, $P<0.0001 ; F_{(4,29)}=97.86, P<0.0001 ; F_{(4,29)}=36.25$, $P<0.0001$, respectively). The injection of $\mathrm{rSj}$-Cys significantly reduced the production of inflammatory cytokines including TNF- $\alpha$, IL- 6 and IL- $1 \beta$ compared to mice with sepsis without treatment (Fig. 4). rSj-Cys at dose of $10 \mu \mathrm{g}$ had the better inhibitory effects on the release of TNF- $\alpha$, IL- 6 and IL- $1 \beta$ compared to the doses of $50 \mu \mathrm{g}$ (ANOVA: $F_{(4,29)}=40.17, P<0.0001 ; F_{(4,29)}=97.86, P<0.0001 ; F_{(4,29)}$ $=36.25, P<0.0001$, respectively), consistent with the survival results that showed the treatment with $\mathrm{rSj}$-Cys at $10 \mu \mathrm{g}$ dose had the highest survival rate (Fig. 3). The treatment with rSj-Cys promoted secretion of IL-10 and TGF$\beta 1$ in sera, and the treatment with $\mathrm{rSj}$-Cys at dose of $10 \mu \mathrm{g}$ had the highest secretion of IL-10 and TGF- $\beta 1$ compared to the doses of $25 \mu \mathrm{g}$ and $50 \mu \mathrm{g}$ (ANOVA: $F_{(4,29)}=19.30$, $P<0.0001 ; F_{(4,29)}=49.44, P<0.0001$ ) (Fig. 4). These data 


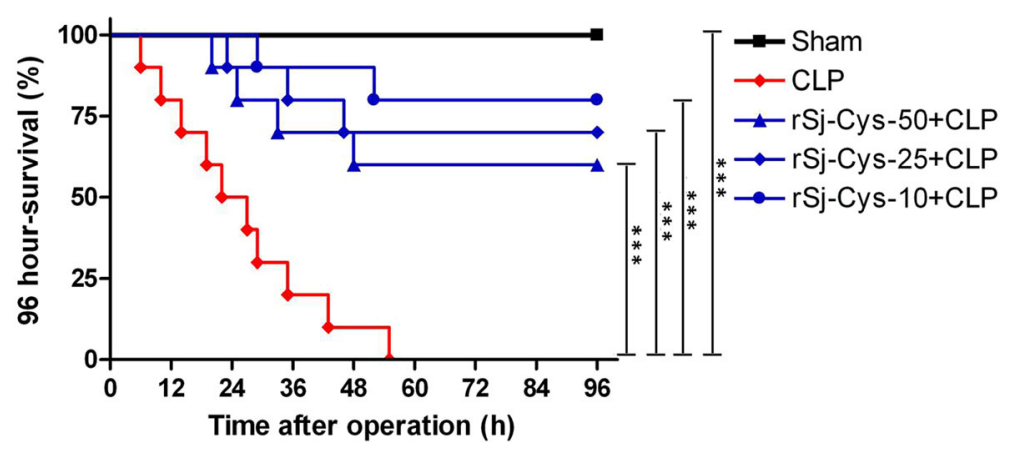

Fig. 3 rSj-Cys treatment reduced mortality of mice with sepsis induced by CLP. After CLP surgery, mice were injected intraperitoneally with different doses of rSj-Cys. Mice with sham surgery and treated with PBS were used as control. The survival rate was determined using KaplanMeier method and compared by log-rank test ( $n=10$ mice per group). ${ }^{* *} P<0.001$
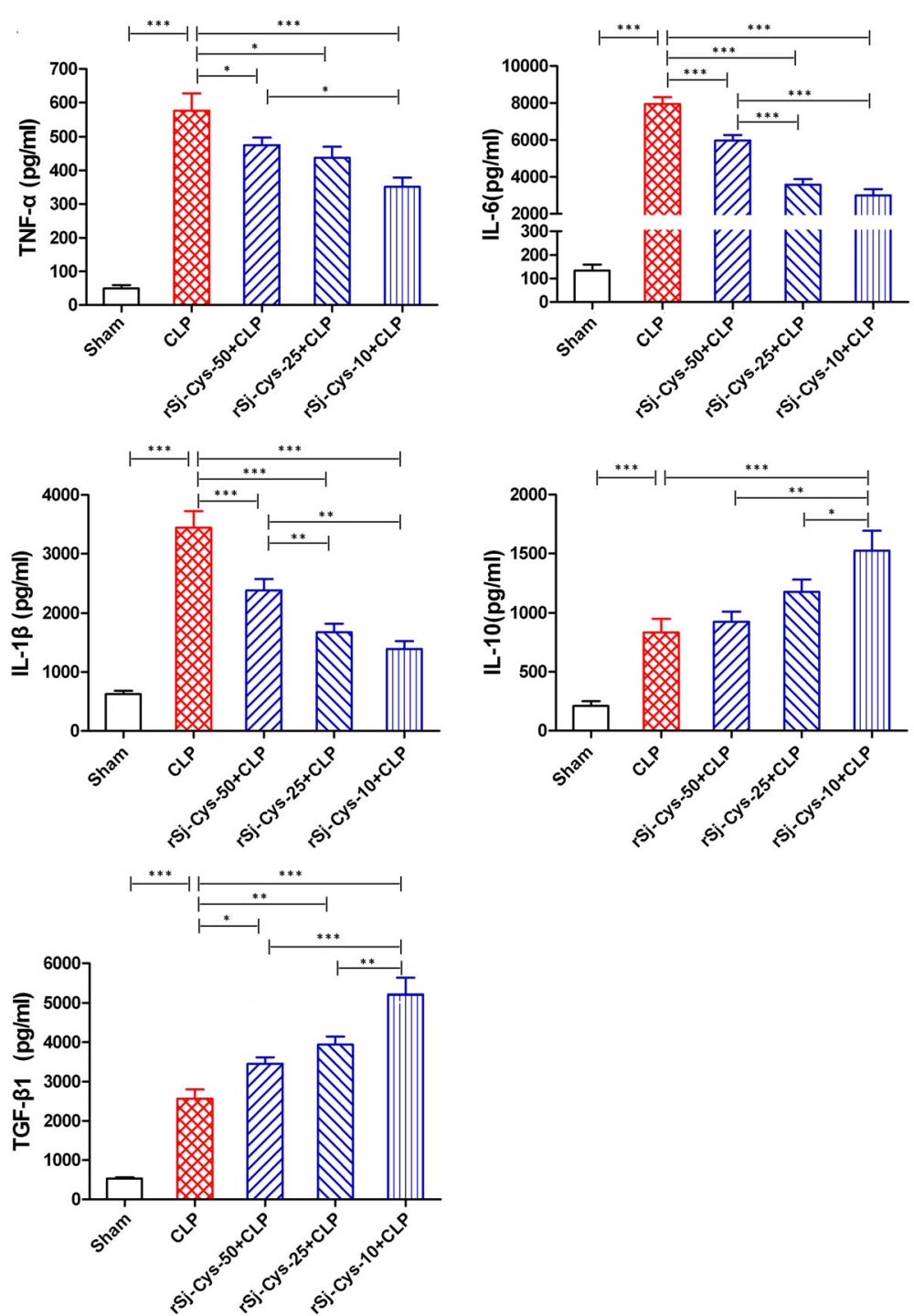

Fig. 4 rSj-Cys reduced the inflammatory cytokines (TNF- $\alpha, I L-6, I L-1 \beta)$ and induced IL-10 and TGF- $\beta 1$ releasing in mice with CLP-induced sepsis. The levels of these cytokines in sera of mice were measured by ELISA $12 \mathrm{~h}$ after the surgery. The results are shown as the mean \pm SEM for each group $(n=6) .{ }^{*} P<0.05,{ }^{* *} P<0.01,{ }^{* * *} P<0.001$ 
indicate that $\mathrm{rSj}$-Cys rescues mice from lethal sepsis through inhibiting systemic inflammatory cytokines possibly through stimulating the secretion of regulatory cytokines such as IL-10 and TGF- $\beta 1$.

rSj-Cys reduces pathology caused by CLP-induced sepsis As rSj-Cys decreased systemic inflammatory cytokines, we examined whether treatment with $\mathrm{rSj}$-Cys prevented injury of some important organs caused by CLP-induced sepsis.

\section{Liver}

The serum levels of ALT, AST were greatly increased of mice with CLP-induced sepsis compared to mice with sham surgery (ANOVA: $F_{(4,29)}=22.39, P<0.0001 ; F_{(4,29)}$ =26.26, $P<0.0001$, respectively), reflecting the serious injury of liver cells (Fig. 5a). Histopathology of liver tissues of mice with sepsis revealed hepatic cords disorder, hepatocytes swelling, inflammatory cell infiltration (Fig. 5b). The liver injury scores was significantly increased in mice with sepsis compared to mice with sham surgery (ANOVA: $F_{(4,29)}=21.31, P<0.0001$ ) (Fig. 5c). After being treated with $\mathrm{rSj}$-Cys, the serum levels of ALT, AST were obviously decreased, and the sepsiscaused liver injury scores was much reduced with the best results for group treated with $10 \mu \mathrm{g}$ of rSj-Cys compared to mice with sepsis without treatment, which is consistent with the highest levels of IL-10 and TGF- $\beta 1$ cytokines and lowest levels of pro-inflammatory cytokines in sera measured above.

\section{Kidney}

The serum levels of BUN and $\mathrm{Cr}$ were also highly increased in mice with CLP-induced sepsis compared to mice with sham surgery (ANOVA: $F_{(4,29)}=17.48, P<0.0001 ; F_{(4,29)}=$ 7.78, $P=0.0003$, respectively), indicating the serious injury of kidney cells (Fig. 6a). The kidney histopathology results revealed that some of glomerulus disrupted and distorted, renal tubular cells edema, plenty of infiltrated inflammatory cells (Fig. 6b) and kidney injury scores was significantly increased in mice with sepsis compared to mice with sham surgery (ANOVA: $F_{(4,29)}=24.68, P<0.0001$ ) (Fig. 6c). After treatment with $\mathrm{rSj}$-Cys, the serum levels of BUN and $\mathrm{Cr}$ were significantly decreased compared to mice with sepsis without treatment, the sepsis-caused kidney injury was mitigated and kidney injury scores was much reduced (ANOVA: $F_{(4,29)}=24.68, P<0.0001$ ) (Fig. 6b, c).

\section{Lung}

The lung sections of mice in sham group exhibited normal lung architecture with no evidence of inflammation, however the lung sections of mice with sepsis showed that the alveolar structural injury, interalveolar septum thickened and disrupted, inflammatory cell infiltration
(Fig. 7a) and lung injury scores was significantly increased in mice with sepsis compared to mice with sham surgery (ANOVA: $F_{(4,29)}=12.11, P<0.0001$ ) (Fig. 7b). After treatment with $\mathrm{rSj}$-Cys, the sepsis-caused lung injury was improved and lung injury scores was much reduced compared to mice with sepsis without treatment, with the best results in group treated with $10 \mu \mathrm{g}$ of $\mathrm{rSj}$-Cys, which is consistent with the highest levels of IL-10 and TGF- $\beta 1$ cytokines and lowest levels of proinflammatory cytokines in sera.

\section{rSj-Cys suppressed the expression of MyD88 with CLP- induced sepsis}

MyD88 is the canonical adaptor for inflammatory TLR signaling pathways. Therefore, we detected the expression of MyD88 in the liver, kidney and lung tissues of mice with sepsis treated with or without $\mathrm{rSj}$-Cys to investigate whether $\mathrm{rSj}$-Cys protect major organ with sepsis through inhibiting MyD88 expression. The results demonstrated that the expression of MyD88 in the liver (Fig. 8a), kidney (Fig. 8b) and lung (Fig. 8c) of mice was remarkably increased $12 \mathrm{~h}$ after CLP surgery compared to mice with sham surgery (ANOVA: $F_{(4,29)}=21.73, P<0.0001 ; F_{(4,29)}=$ 35.97, $P<0.0001 ; F_{(4,29)}=45.76, P<0.0001$, respectively). Treatment with $\mathrm{rSj}$-Cys significantly suppressed the expression of MyD88 in these tissues. rSj-Cys at dose of $10 \mu \mathrm{g}$ had the better inhibitory effects on the expression of MyD88 than the doses of $50 \mu \mathrm{g}$ compared to mice with sepsis without treatment in liver (Fig. 8a) and in lung (Fig. 8c). As a control, the level of $\beta$-actin was the same in all treated groups (Fig. 8).

\section{Discussion}

Sepsis is still one of the leading causes of mortality in surgical patients or patients in intensive care units with $30-70 \%$ mortality for severe sepsis [38]. The superinfection of bacteria in blood leads to the release of large amount of LPS that induces severe inflammatory reaction called systemic inflammatory response syndrome (SIRS) [39]. The out-of-control inflammation eventually results in organ failure and even death. Reduction of pro-inflammatory immune responses during SIRS could improve survival of bacteria-induced sepsis [40]. Previous studies have determined that $S$. japonicum-secreted Sj-Cys could stimulate CD $4^{+} \mathrm{CD} 25^{+}$Foxp $3^{+}$Treg cells [31], alleviate the Th1 dominated immunopathogenesis and actively restrain the colonic inflammation in TNBSinduced experimental colitis in mice [29]. In order to evaluate whether Sj-Cys modulates the immune response of mice with sepsis to avoid over-inflammatory reaction to bacterial infection, we first tested if $\mathrm{rSj}$-Cys was able to modulate the functions of macrophages because published evidence showed that macrophages play an important role in inflammation upon infections 

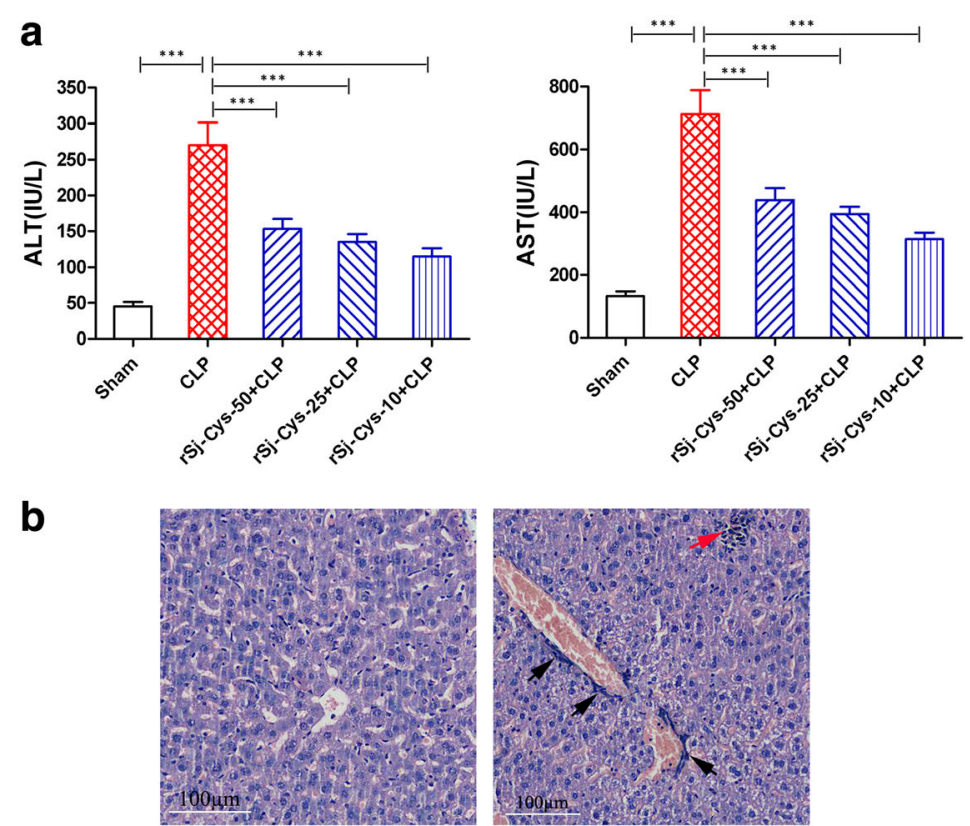

Sham

CLP

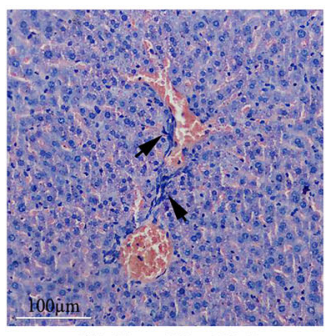

rSj-Cys-50+CLP

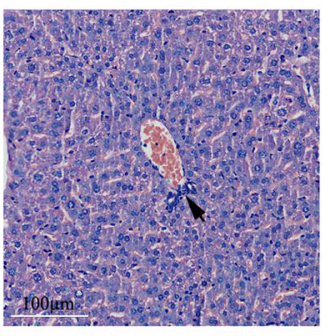

rSj-Cys-25+CLP

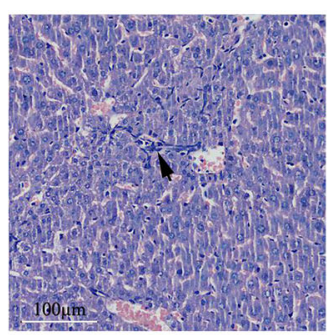

rSj-Cys-10+CLP

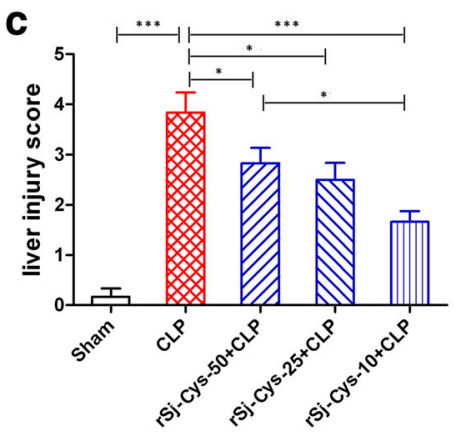

Fig. 5 rSj-Cys reduced liver injury caused by CLP-induced sepsis. a The serum levels of ALT and AST were reduced in mice treated with rSj-Cys. b Representative liver sections showing reduced hepatocytes swelling and inflammatory cell infiltration in rSj-Cys treated mice ( $\times 200$; Scale-bars: $100 \mu \mathrm{m})($ red arrow: hepatocellular necrosis; black arrow: inflammatory cell) and the improved liver injury score in rSj-Cys treated mice (c). The results are shown as the mean \pm SEM for each group $(n=6) .{ }^{*} P<0.05,{ }^{* * *} P<0.001$

mainly via secreting inflammatory mediators such as pro-inflammatory cytokines [41, 42]. Gram-negative bacteria release LPS that binds on the TLR4 receptor on macrophages resulting in the release of proinflammatory mediators such as TNF- $\alpha$, IL-6, IL- $1 \beta$ and IL-12 [41, 43]. The murine peritoneal exudate cells (PECs) were collected from donor mice as macrophage source and stimulated by LPS in the presence of $\mathrm{rSj}$ -
Cys. We observed that $\mathrm{rSj}$-Cys significantly inhibited the LPS-stimulated macrophages to release lower proinflammatory cytokines and inflammatory mediator NO in vitro, indicating $\mathrm{rSj}$-Cys has direct inhibitory effects on macrophages' response agonist LPS. These results in vitro are consistent with those results in vivo showing chronic infection of Litomosoides sigmodontis protected mice from bacteremia through inhibiting the level of 

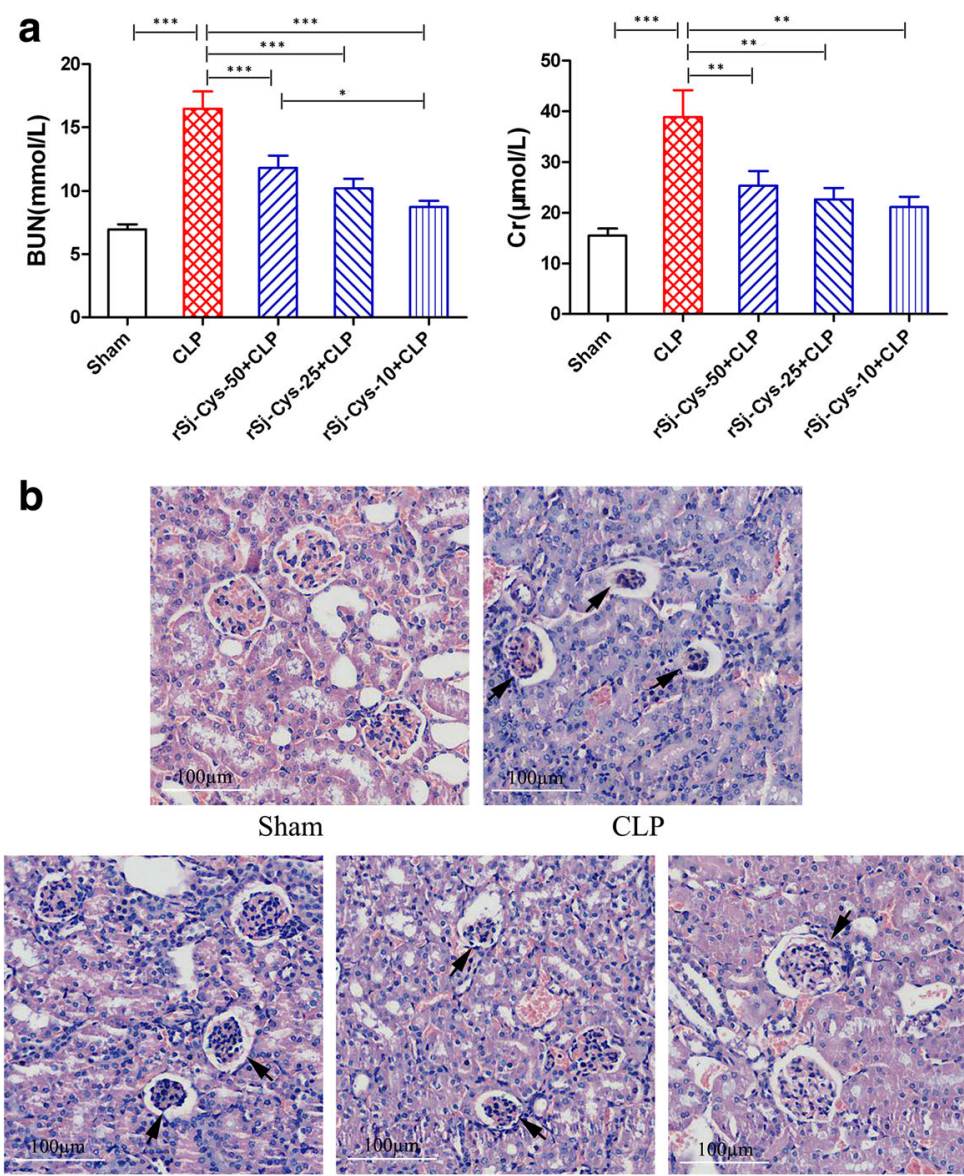

rSj-Cys-50+CLP

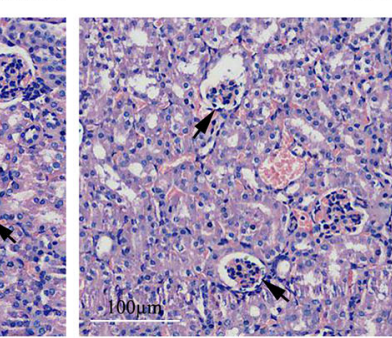

rSj-Cys-25+CLP

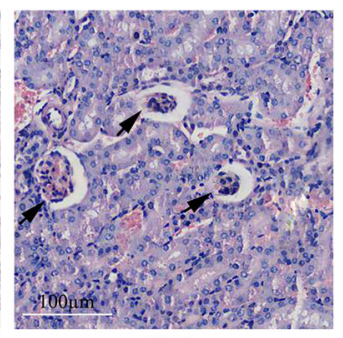

CLP

C

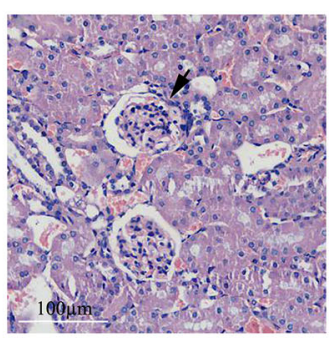

rSj-Cys-10+CLP

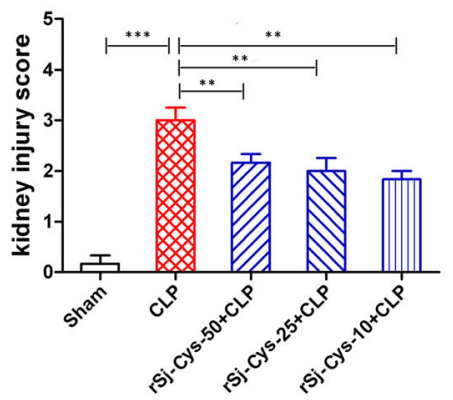

Fig. 6 rSj-Cys reduced kidney injury caused by CLP-induced sepsis. a The serum levels of BUN and Cr were reduced in mice treated with rSj-Cys. b Representative kidney sections showing reduced renal tissue disrupture and inflammatory cell infiltration in rSj-Cys treated mice ( $\times 200$; Scalebars: $100 \mu \mathrm{m}$ ) (arrows indicate shrunk glomerulus) and the improved kidney injury score (c). The results are shown as the mean \pm SEM for each group $(n=6) .{ }^{*} P<0.05,{ }^{* *} P<0.01,{ }^{* * *} P<0.001$

pro-inflammatory cytokines/chemokines produced by macrophages [44].

Secondly, we treated the mice with CLP-induced sepsis [40] with different dose of $\mathrm{rSj}$-Cys. Strikingly, treatment with $\mathrm{rSj}$-Cys significantly reduced the mortality of mice with CLP-induced sepsis in this study. Mice treated with $10 \mu \mathrm{g}$ of $\mathrm{rSj}$-Cys protein exhibited $80 \%$ survival $96 \mathrm{~h}$ after CLP surgery compared to those without treatment that all died $55 \mathrm{~h}$ after CLP surgery. Pathological results also showed that sepsis mice treated with $10 \mu \mathrm{g}$ of $\mathrm{rSj}$ Cys protein remarkably reduced the pathology of important organs (liver, kidney and lung) with much less tissue injury and inflammatory cell infiltration. The therapeutic effects of $\mathrm{rSj}$-Cys treatment were associated with the significant reduction of pro-inflammatory cytokines (TNF- $\alpha$, IL-1 $\beta$ and IL- 6 ) and boost of IL-10 and 


\section{a}

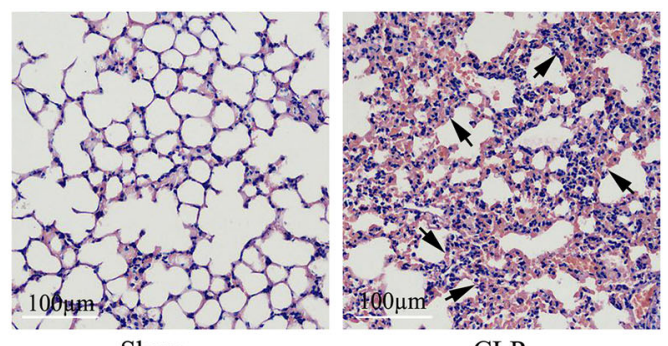

Sham

CLP

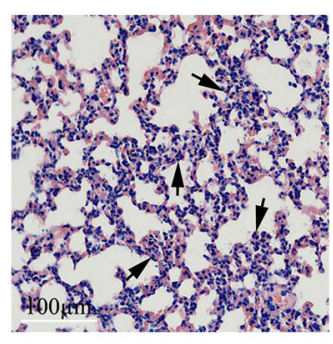

rSj-Cys-50+CLP

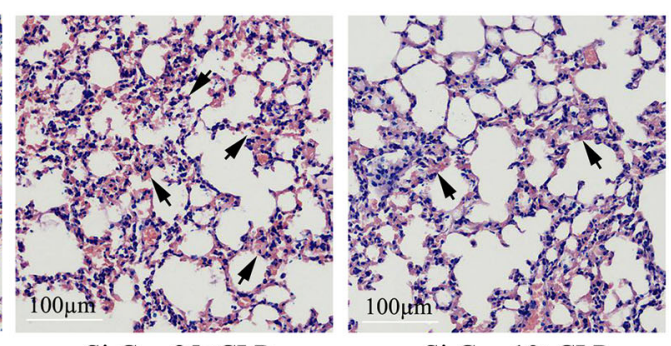

rSj-Cys-25+CLP

rSj-Cys-10+CLP

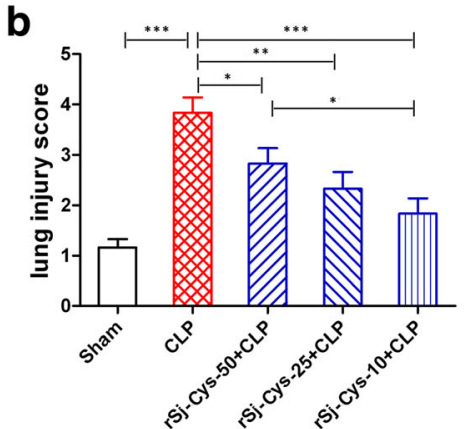

Fig. 7 rSj-Cys reduced lung injury caused by CLP-induced sepsis. a Representative lung tissue sections showing reduced alveolar structural disruption and reduced inflammatory cell infiltration in $\mathrm{rSj}$-Cys treated mice $(\times 200$; Scale-bars: $100 \mu \mathrm{m})$ (arrows indicate interalveolar septum thickened). $\mathbf{b}$ The improved lung injury score based on the tissue injury. The results are shown as the means \pm SEM for each group $(n=6)$. ${ }^{*} P<0.05,{ }^{* *} P<0.01,{ }^{* * *} P<0.001$

TGF- $\beta 1$ cytokines in sera of mice with sepsis. The results indicate that $\mathrm{rSj}$-Cys is a potent agent in immunomodulating mice immune system to reduce the inflammatory responses possibly through stimulating the regulatory cytokines such as IL-10 and TGF- $\beta 1$, so as to protect mice with sepsis from over-inflammatory reaction to bacterial infection that eventually leads to serious organ damage or even to death. IL-10 is usually produced by monocytes and Th1 and Th2 lymphocytes with a general inhibitory function to suppress lymphocyte proliferation and cytokine responses. TGF- $\beta 1$ is produced by most of immune cells including lymphocytes, with various functions to affect $\mathrm{T}$ cell proliferation, differentiation and antigen presentation [45]. Regulatory $\mathrm{T}$ cells (Tregs) play crucial roles in modulating immune responses mostly through secretion of IL-10, TGF- $\beta 1$ [14]. Induction of IL-10 has been proven to be essential in the immunomodulation of host immune system that reduce inflammatory responses to helminth infections and to autoimmune/ inflammatory diseases [25-28]. IL10 has also been proven to be essential in preventing lethal endotoxic shock because depletion of IL-10 resulted in increased mortality in an endotoxemia model [46]. In this study, we identified that treatment with $\mathrm{rSj}$-Cys eventually reduced the expression of MyD88 in liver, kidney and lung tissues. MyD88 is the canonical adaptor for inflammatory TLR signaling pathways [47]. The possible mechanism underlying the therapeutic effect of $\mathrm{rSj}$ Cys is that administration of $\mathrm{rSj}$-Cys stimulates Tregs and/or immune cells to produce regulatory cytokines such as IL-10 and TGF- $\beta 1$ that inhibit the production of pro-inflammatory cytokines through suppressing TLRMyD88 activation signal pathway as other helminthderived proteins did [48-51].

However, in this study the therapeutic effect of $\mathrm{rSj}$-Cys on sepsis does not seem to be dose-dependent. We found that $10 \mu \mathrm{g}$ of $\mathrm{rSj}$-Cys had the better therapeutic efficacy to reduce the severity of sepsis than the dose of 

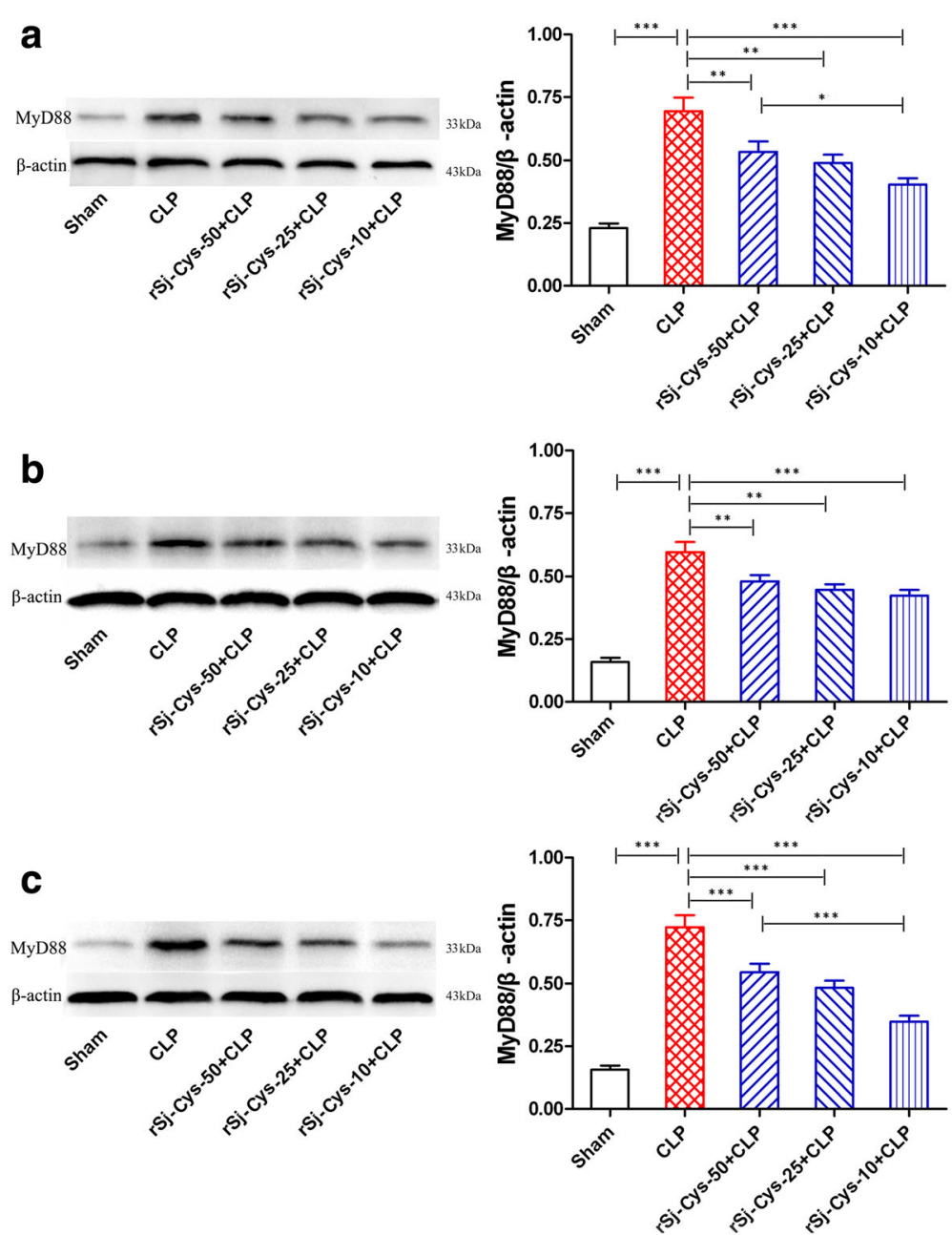

Fig. 8 rSj-Cys suppressed the expression of MyD88 in liver (a), kidney (b) and lung (c) of mice with CLP-induced sepsis detected by western blot. The $\beta$-actin was detected as control. The density ratio of MyD88/ $\beta$-actin is shown on the right. The results are shown as the density mean \pm SEM for each group $(n=6) .{ }^{*} P<0.05,{ }^{* *} P<0.01,{ }^{* * *} P<0.001$

$25 \mu \mathrm{g}$ or $50 \mu \mathrm{g}$ of $\mathrm{rSj}$-Cys administrated, which is consistent with the higher levels of IL-10 and TGF- $\beta 1$ and lower levels of pro-inflammatory cytokines in group of $10 \mu \mathrm{g} \mathrm{rSj-Cys,} \mathrm{possibly} \mathrm{overdose} \mathrm{of} \mathrm{rSj}$-Cys saturates the effect on immune cells or blocks the receptors for other immunomodulatory factors. Another possible reason is that bacteria-expressed $\mathrm{rSj}$-Cys may contain some trace of bacterial components or LPS or other immune enhancers even though the LPS level was under control during production of recombinant $\mathrm{Sj}$-Cys $(<0.06 \mathrm{EU} / \mathrm{ml})$.

In this study we identified that $\mathrm{rSj}$-Cys owns a therapeutic effect on CLP-induced sepsis through downregulating the TLR adaptor-transducer MyD88 pathway. Other helminth infection or worm-derived materials showed the therapeutic effects on alleviating sepsis through different mechanisms [37, 52-54] such as producing antibody antiCyclophilin A, an important inflammatory factor that plays a significant role in the development process of sepsis [53]. Whether other immunological mechanisms or pathways are involved in the protection of $\mathrm{Sj}$-Cys against bacteremia-induced excessive inflammation is under investigation.

\section{Conclusions}

Sj-Cys, a cysteine protease inhibitor secreted by S. japonicum, is a strong immunomodulator that alleviates excessive inflammation caused by bacteremia through stimulating IL10 and TGF- $\beta 1$ cytokines and reducing pro-inflammatory cytokines TNF- $\alpha$, IL-6, IL-1 $\beta$, possibly acts on macrophages or other effective immune cells via downregulation of the TLR adaptor-transducer MyD88. As a result, treatment with $\mathrm{rSj}$-Cys significantly reduced the multiple organ damage caused by CLP-induced sepsis and provided a therapeutic effect on bacterial sepsis in a mice model. 


\section{Abbreviations}

ALT: Alanine transaminase; AST: Aspartate transaminase; BUN: Blood urea nitrogen; CLP: Cecal ligation and puncture; Cr: Creatinine; ELISA: Enzymelinked immunosorbent assay; IL-10: Interleukin 10; IL-1ß: Interleukin 1ß; IL6: Interleukin 6; LPS: Lipopolysaccharides; MODS: Multiple organ dysfunction syndromes; NO: Nitrous oxide; PECs: Peritoneal exudate cells; TGF-

$\beta 1$ : Transforming growth factor- $\beta 1$; TNBS: Trinitrobenzene sulfonic acid.; TNFa: Tumor necrosis factor alpha; Tregs: Regulatory $T$ cells

\section{Acknowledgments}

We thank Dr. Li He at Basic Medical School of Wuhan University, for providing recombinant plasmid.

\section{Funding}

The work was funded by the National Science Foundation of China (No. 81441120), Scientific Research Innovation Platform Team of University (No. 2016-40), Science Foundation of Anhui Province (No. 1508085QH158; No. 1608085QC51; No. 1608085QH207), Key Supporting Project of Prominent Youth in Universities of Anhui (No. gxyqZD2016159), Program of Natural Science Foundation of the Anhui Higher Education Institutions (No. KJ2017A235; No. KJ2015B013by; No. KJ2016A489).

\section{Availability of data and materials}

The datasets generated and/or analysed during the current study are available from the corresponding author on reasonable request.

\section{Authors' contributions}

XDY, HHL and BZ conceived and designed the study; HHL, SSW, NL, YKW, HZ and XZC performed the experiments; WXH, DPQ, LC and QF analyzed the data; HHL wrote the manuscript. BZ, XDY and JLS critically revised the manuscript. All authors read and approved the final manuscript.

\section{Competing interests}

The authors declare that they have no competing interests.

\section{Consent for publication}

Not applicable.

\section{Ethics approval and consent to participate}

All procedures concerning to laboratory animals were in strict accordance with the Chinese National Institute of Health Guide for the Care and Use of Laboratory Animals, and approved by the Animal Care and Use Committee of Anhui Medical University (approval\#: AMU26-08061)

\section{Publisher's Note}

Springer Nature remains neutral with regard to jurisdictional claims in published maps and institutional affiliations.

\section{Author details \\ ${ }^{1}$ Basic Medical College of Bengbu Medical College, Bengbu 233000, China. \\ ${ }^{2}$ Anhui Key Laboratory of Infection and Immunity of Bengbu Medical College, Bengbu 233000, China. ${ }^{3}$ Pediatrics Department of Affiliated Provincial Hospital of Anhui Medical University, Hefei 230001, China. ${ }^{4}$ Section of Tropical Medicine, Department of Pediatrics, Baylor College of Medicine, Houston, TX, USA. ${ }^{5}$ Second Affiliated Hospital of Bengbu Medical College, Bengbu 233000, China. ${ }^{6}$ Department of Immunology, Anhui Medical University, Hefei 230022, China.}

Received: 29 November 2016 Accepted: 1 May 2017 Published online: 08 May 2017

\section{References}

1. Rhodes A, Phillips G, Beale R, Cecconi M, Chiche JD, De Backer D, et al. The surviving sepsis campaign bundles and outcome: results from the International Multicentre Prevalence Study on Sepsis (the IMPreSS study). Intensive Care Med. 2015:41:1620-8.

2. Lakshmikanth $\mathrm{CL}$, Jacob SP, Chaithra VH, de Castro-Faria-Neto HC, Marathe GK. Sepsis: in search of cure. Inflamm Res. 2016;65:587-602.

3. Dejager L, Pinheiro I, Dejonckheere E, Libert C. Cecal ligation and puncture: the gold standard model for polymicrobial sepsis? Trends Microbiol. 2011; 19:198-208.
4. Angus DC, Linde-Zwirble WT, Lidicker J, Clermont G, Carcillo J, Pinsky MR. Epidemiology of severe sepsis in the United States: analysis of incidence, outcome, and associated costs of care. Crit Care Med. 2001;29:1303-10.

5. Huang L, Wang C, Naren G, Aori G. Effect of geniposide on LPS-induced activation of TLR4-NF-kappaB pathway in RAW264.7 macrophage cell line. Chin J Cell Mol Imm. 2013:29:1012-4.

6. Schulte W, Bernhagen J, Bucala R. Cytokines in sepsis: potent immunoregulators and potential therapeutic targets - an updated view. Mediat Inflamm. 2013;2013:165974.

7. Gómez H, Kellum JA. Sepsis-induced acute kidney injury. Curr Opin Crit Care. 2016:22:546-53.

8. Wang P, Huang J, Li Y, Chang R, Wu H, Lin J, et al. Exogenous carbon monoxide decreases sepsis-induced acute kidney injury and inhibits NLRP3 inflammasome activation in rats. Int J Mol Sci. 2015;16:20595-608.

9. Li H, Qiu D, Gao Q, Wang H, Sun M. Selectively activating melanocortin 4 receptor acts against rat sepsis-induced acute liver injury via HMGB1/TLR4/ NF-kB signaling pathway. Chin J Cell Mol Imm. 2016:32:1055-9.

10. Yan J, Li S, Li S. The role of the liver in sepsis. Int Rev Immunol. 2014;33:498-510.

11. Drechsler S, Weixelbaumer KM, Weidinger A, Raeven P, Khadem A, Redl H, et al. Why do they die? Comparison of selected aspects of organ injury and dysfunction in mice surviving and dying in acute abdominal sepsis. Intensive Care Med Exp. 2015;3:48.

12. Allen JE, Maizels RM. Diversity and dialogue in immunity to helminths. Nat Rev Immunol. 2011;11:375-88.

13. Shepherd C, Navarro S, Wangchuk P, Wilson D, Daly NL, Loukas A Identifying the immunomodulatory components of helminths. Parasite Immunol. 2015;37:293-303.

14. van der Vlugt LE, Labuda LA, Ozir-Fazalalikhan A, Lievers E, Gloudemans AK, Liu KY, et al. Schistosomes induce regulatory features in human and mouse CD1d(hi) B cells: inhibition of allergic inflammation by $\mathrm{LL}-10$ and regulatory T cells. PLoS One. 2012;7, e30883.

15. Elliott DE, Weinstock JV. Helminth-host immunological interactions: prevention and control of immune-mediated diseases. Ann NY Acad Sci. 2012;1247:83-96.

16. Elliott DE, Summers RW, Weinstock JV. Helminths as governors of immunemediated inflammation. Int J Parasitol. 2007:37:457-64.

17. Dittrich AM, Erbacher A, Specht S, Diesner F, Krokowski M, Avagyan A, et al. Helminth infection with Litomosoides sigmodontis induces regulatory $T$ cells and inhibits allergic sensitization, airway inflammation, and hyperreactivity in a murine asthma model. J Immunol. 2008;180:1792-9.

18. Hübner MP, Shi Y, Torrero MN, Mueller E, Larson D, Soloviova K, et al. Helminth protection against autoimmune diabetes in nonobese diabetic mice is independent of a type 2 immune shift and requires TGF-beta. J Immunol. 2012;188:559-68.

19. Kordis D, Turk V. Phylogenomic analysis of the cystatin superfamily in eukaryotes and prokaryotes. BMC Evol Biol. 2009;9:266.

20. Hartmann S, Adam R, Marti T, Kirsten C, Seidinger S, Lucius R. A 41-kDa antigen of the rodent filaria Acanthocheilonema viteae with homologies to tropomyosin induces host-protective immune responses. Parasitol Res. 1997; 83:390-3

21. Hartmann S, Kyewski B, Sonnenburg B, Lucius R. A filarial cysteine protease inhibitor down-regulates T cell proliferation and enhances interleukin-10 production. Eur J Immunol. 1997:27:2253-60.

22. Manoury B, Gregory WF, Maizels RM, Watts C. Bm-CPI-2, a cystatin homolog secreted by the filarial parasite Brugia malayi, inhibits class II MHC-restricted antigen processing. Curr Biol. 2001;11:447-51.

23. Schierack P, Lucius R, Sonnenburg B, Schilling K, Hartmann S. Parasite-specific immunomodulatory functions of filarial cystatin. Infect Immun. 2003;71:2422-9.

24. Harnett W. Secretory products of helminth parasites as immunomodulators. Mol Biochem Parasitol. 2014:195:130-6

25. Yang X, Liu J, Yue Y, Chen W, Song M, Zhan X, et al. Cloning, expression and characterisation of a type II cystatin from Schistosoma japonicum, which could regulate macrophage activation. Parasitol Res. 2014:113:3985-92.

26. Schnoeller C, Rausch S, Pillai S, Avagyan A, Wittig BM, Loddenkemper C, et al. A helminth immunomodulator reduces allergic and inflammatory responses by induction of IL-10-producing macrophages. J Immunol. 2008; 180:4265-72.

27. Jang SW, Cho MK, Park MK, Kang SA, Na BK, Ahn SC, et al. Parasitic helminth cystatin inhibits DSS-induced intestinal inflammation via IL-10(+)F4/80(+) macrophage recruitment. Korean J Parasitol. 2011;49:245-54. 
28. Sun Y, Liu G, Li Z, Chen Y, Liu Y, Liu B, et al. Modulation of dendritic cell function and immune response by cysteine protease inhibitor from murine nematode parasite Heligmosomoides polygyrus. Immunology. 2013;138:370-81.

29. Wang S, Xie Y, Yang X, Wang X, Yan K, Zhong Z, et al. Therapeutic potential of recombinant cystatin from Schistosoma japonicum in TNBS-induced experimental colitis of mice. Parasit Vectors. 2016;9:6.

30. Liu F, Cheng W, Pappoe F, Hu X, Wen H, Luo Q, et al. Schistosoma japonicum cystatin attenuates murine collagen-induced arthritis. Parasitol Res. 2016;115:3795-806.

31. He B, Cai G, Ni Y, Li Y, Zong H, He L. Characterization and expression of a novel cystatin gene from Schistosoma japonicum. Mol Cell Probes. 2011;25: 186-93.

32. Ashley SL, Welton AR, Harwood KM, Van Rooijen N, Spindler KR. Mouse adenovirus type 1 infection of macrophages. Virology. 2009;390:307-14.

33. Ito S, Tanaka Y, Oshino R, Okado S, Hori M, Isobe Kl. GADD34 suppresses lipopolysaccharide-induced sepsis and tissue injury through the regulation of macrophage activation. Cell Death Dis. 2016;7, e2219.

34. Gandolfo MT, Jang HR, Bagnasco SM, Ko GJ, Agreda P, Satpute SR, et al. Foxp3+ regulatory $T$ cells participate in repair of ischemic acute kidney injury. Kidney Int. 2009;76:717-29.

35. Hu J, Zhang L, Wang N, Ding R, Cui S, Zhu F, et al. Mesenchymal stem cells attenuate ischemic acute kidney injury by inducing regulatory $T$ cells through splenocyte interactions. Kidney Int. 2013;84:521-31.

36. D'Alessio FR, Tsushima K, Aggarwal NR, West EE, Willett MH, Britos MF, et al. CD4 + CD25 + Foxp3+ Tregs resolve experimental lung injury in mice and are present in humans with acute lung injury. J Clin Invest. 2009;119:2898-913.

37. Hubner MP, Layland LE, Hoerauf A. Helminths and their implication in sepsis a new branch of their immunomodulatory behaviour? Pathog Dis. 2013;69: 127-41.

38. Beale R, Reinhart K, Brunkhorst FM, Dobb G, Levy M, Martin G, et al. Promoting Global Research Excellence in Severe Sepsis (PROGRESS): lessons from an international sepsis registry. Infection. 2009;37:222-32.

39. Morrell MR, Micek ST, Kollef MH. The management of severe sepsis and septic shock. Infect Dis Clin North Am. 2009:23:485-501.

40. Niiyama S, Takasu O, Sakamoto T, Ushijima K. Intraperitoneal adipose tissue is strongly related to survival rate in a mouse cecal ligation and puncture model. Clin Transl Immunol. 2016;5, e64.

41. Van Amersfoort ES, Van Berkel TJ, Kuiper J. Receptors, mediators, and mechanisms involved in bacterial sepsis and septic shock. Clin Microbiol Rev. 2003:16:379-414.

42. Cailhier JF, Partolina M, Vuthoori S, Wu S, Ko K, Watson S, et al. Conditional macrophage ablation demonstrates that resident macrophages initiate acute peritoneal inflammation. J Immunol. 2005;174:2336-42.

43. Martinon F, Mayor A, Tschopp J. The inflammasomes: guardians of the body. Annu Rev Immunol. 2009;27:229-65.

44. Gondorf F, Berbudi A, Buerfent BC, Ajendra J, Bloemker D, Specht S, et al. Chronic filarial infection provides protection against bacterial sepsis by functionally reprogramming macrophages. PLoS Pathog. 2015;11, e1004616.

45. Jutel M, Akdis M, Budak F, Aebischer-Casaulta C, Wrzyszcz M, Blaser K, et al. $\mathrm{IL}-10$ and TGF-beta cooperate in the regulatory $T$ cell response to mucosal allergens in normal immunity and specific immunotherapy. Eur J Immunol. 2003;33:1205-14.

46. Berg DJ, Kuhn R, Rajewsky K, Muller W, Menon S, Davidson N, et al. Interleukin-10 is a central regulator of the response to LPS in murine models of endotoxic shock and the Shwartzman reaction but not endotoxin tolerance. J Clin Invest. 1995;96:2339-47.

47. Warner N, Nunez G. MyD88: a critical adaptor protein in innate immunity signal transduction. J Immunol. 2013;190:3-4.

48. Puneet P, McGrath MA, Tay HK, Al-Riyami L, Rzepecka J, Moochhala SM, et al. The helminth product ES-62 protects against septic shock via Toll-like receptor 4-dependent autophagosomal degradation of the adaptor MyD88. Nat Immunol. 2011:12:344-51.

49. Du L, Liu L, Yu Y, Shan H, Li L. Trichinella spiralis excretory-secretory products protect against polymicrobial sepsis by suppressing MyD88 via mannose receptor. Biomed Res Int. 2014;2014:898646.

50. Turner JD, Langley RS, Johnston KL, Egerton G, Wanji S, Taylor MJ. Wolbachia endosymbiotic bacteria of Brugia malayi mediate macrophage tolerance to TLR- and CD40-specific stimuli in a MyD88/TLR2-dependent manner. J Immunol. 2006;177:1240-9.

51. Martin I, Caban-Hernandez K, Figueroa-Santiago O, Espino AM. Fasciola hepatica fatty acid binding protein inhibits TLR4 activation and suppresses the inflammatory cytokines induced by lipopolysaccharide in vitro and in vivo. J Immunol. 2015;194:3924-36.

52. Li HH, He WX, Song D, Wu Q, Li N, Wan YK, et al. Effect of Trichinella spiralis and its worm-derived proteins on CLP-induced sepsis in mice. J South Med Univ. 2016;36:1048-54

53. Song $T$, Yang $M$, Chen J, Huang L, Yin H, He T, et al. Prognosis of sepsis induced by cecal ligation and puncture in mice improved by anti-Clonorchis sinensis cyclopholin a antibodies. Parasit Vectors. 2015;8:502.

54. Yang X, He W, Fang Q, Song D, Wu Q, Wang X, et al. Effect of excretory/ secretory protein of Trichinella spiralis adult worm on CLP-induced sepsis in mice. Chin J Schi Contl 2016:28:293-6.

\section{Submit your next manuscript to BioMed Central and we will help you at every step:}

- We accept pre-submission inquiries

- Our selector tool helps you to find the most relevant journal

- We provide round the clock customer support

- Convenient online submission

- Thorough peer review

- Inclusion in PubMed and all major indexing services

- Maximum visibility for your research

Submit your manuscript at www.biomedcentral.com/submit
Biomed Central 